\title{
Cobalt aluminum silicate complexes prepared by the non-hydrolytic sol-gel route and their catalytic activity in hydrocarbon oxidation
}

\author{
B.L. Caetano ${ }^{\text {a }}$, L.A. Rocha ${ }^{\text {a }}$, E. Molina ${ }^{\text {a }}$, Z.N. Rocha ${ }^{\text {b }}$, G. Ricci ${ }^{\text {a }}$, P.S. Calefi ${ }^{\text {a }}$, \\ O.J. de Lima ${ }^{a}$, C. Mello ${ }^{\text {a }}$, E.J. Nassar ${ }^{\text {a }}$, K.J. Ciuffi ${ }^{\text {a } *}$ \\ ${ }^{a}$ Universidade de Franca, Av. Dr. Armando Salles Oliveira, 201, CP. 82, CEP 14404-600, Franca-SP, Brazil \\ ${ }^{\mathrm{b}}$ Universidade Federal da Bahia, UFBA, Salvador-BA, Brazil \\ Received 13 April 2006; received in revised form 31 May 2006; accepted 11 June 2006
}

\begin{abstract}
This work describes the optimized conditions for the preparation of cobalt aluminum silicate complexes through a simplified methodology. These materials, designated CoAlSi-NHG, were obtained by a non-hydrolytic sol-gel route involving the condensation of aluminum chloride with diisopropylether in the presence of cobalt chloride, followed by reaction with tetraethoxysilane. The obtained solids were heat-treated at various temperatures, and the resulting materials were characterized by ultraviolet-visible spectroscopy, X-ray diffraction, ${ }^{29} \mathrm{Si}$ and ${ }^{27} \mathrm{Al} \mathrm{NMR}$, transmission electron microscopy, surface area, thermogravimetric analysis, and differential thermal analysis. All the materials consisted of an aluminum silicate matrix, and they all remained amorphous throughout heat treatment up to $750{ }^{\circ} \mathrm{C}$. The onset of crystallization took place at $1000{ }^{\circ} \mathrm{C}$, and the formation of mullite was observed thereafter. All the CoAlSi-NHGs obtained in this work via different heat treatments were used as catalysts in the oxidation of $(Z)$-cyclooctene, cyclohexane, and $n$-heptane by iodozylbenzene. The non-hydrolytic sol-gel route led to the obtention of extremely interesting catalytic systems capable of selectively oxidizing various types of reactions. The intermediate species is the oxidizing species oxo-cobalt, which is similar to the active species obtained in the case of enzymes such as cytochrome P-450.
\end{abstract}

(C) 2006 Elsevier B.V. All rights reserved.

Keywords: Cobalt; Non-hydrolytic route; Selective oxidation

\section{Introduction}

Catalysis is the base of many chemical processes that transform cheap and abundant raw material into highly expensive products important for the needs of mankind. Not only are catalytic technologies important from an economic point-of-view, but they are also related to environmental sustainability [1-5]. As very well emphasized by Cusumano [6], catalytic science will play a central role in the viabilization of a sustainable environment in the 21 st century.

The controlled oxidation of alkanes, alkenes, and aromatic hydrocarbons is one of the most important technologies for conversion of oil derivatives into chemistry comodities of high commercial value [7-10]. A very good example is the oxidation of cyclohexane, which furnishes cyclohexanone, a compound that is used as feedstock in several industrial processes

\footnotetext{
* Corresponding author. Tel.: +55 163711 8871/8878; fax: +55 1637118878 . E-mail address: ciuffi@unifran.br (K.J. Ciuffi).
}

including the production of fibres [11-15]. The routes normally employed in this process make use of metallic catalysts such as cobalt salts to promote reaction speed and selectivity. However, there are disadvantages to these processes, such as high energy consumption and low selectivity toward the desired products, which lead to the generation of unwanted byproducts $[12,13]$.

In Nature, various enzymes containing a heme or a non-heme group as the active site; e.g., cytochromes P-450 and methanemonooxygenases, respectively, are capable of carrying out the selective oxidation of hydrocarbons under mild conditions [16,17]. Therefore, there is great interest in mimicking the active sites of these enzymes, isolated by proteins like globin in the case of cytochrome P450, so as to build efficient and selective catalysts. The "isolated site principle" allows control of substrate access to the active site, thus tuning the selectivity of the oxidation reaction [16,17]. Cavity size and shape in the enzymes arrange the hydrocarbon for hydroxilation.

Despite the fact that many model systems have been reported for these enzymes, few works have been successful in mimicking their biological selectivity, especially with respect 
to cyclohexane oxidation [18]. An alternative approach to overcoming the deficiencies of such model systems has been to employ heterogeneous catalysis [19-21].

Heterogeneous catalysis involves the use of a solid inorganic matrix containing active sites on its surface. These sites are capable of affecting the kinetics of chemical reactions. The solid materials' active phase may consist of either a metalloporphyrin containing a transition metal (most often iron or manganese), or a metallic transition metal in its metallic state or in the form of a salt or oxide.

A wide variety of materials can be used as support, where the active phase is stabilized. The most common ones consist of simple metal oxides, such as alumina, silica, aluminum silicates, and titanates. In these supports, the metals may be either entrapped in the pores of the polymeric matrix or intercalated between the constituents of the polymeric backbone, or they may even replace one of the constituents on the support [22-24].

The main advantages of heterogeneous catalysis are a better control of the environment and reaction conditions, thus preventing catalyst self-destruction; higher catalyst stability; higher active site dispersion because of the high surface areas furnished by the support; and catalyst recovery and recycling, which minimizes cost and generates less environmental pollution.

Various methods have been used in the preparation of polymeric matrices that could serve as catalyst support, and the sol-gel process has proven to be a valuable tool for these preparations because it allows the control of various parameters that are essential for regioselective and shape-selective catalysis [21].

Conventional sol-gel routes involve hydrolysis and condensation of metal alkoxides under controlled $\mathrm{pH}$ conditions. Homogeneity at the molecular level is difficult to achieve in the preparation of heterometallic oxides as well as in the synthesis of organic-inorganic hybrids because of the different reactivities of the various precursors toward hydrolysis and condensation. Non-hydrolytic processes [25-30] are very attractive alternatives for the synthesis of multicomponent oxides since they allow the reaction of metal halides with metal alkoxides through the in situ formation of an alkyl halide.

Cobalt-based catalysts are important materials in the field of heterogeneous catalysis, especially in the case of hydrogenation, hydrotreating, and combustion processes [31]. Cobalt complexes are interesting materials not only because they are relatively inexpensive and have a low water-gas shift activity, but also because of the rich spectroscopy of the cobalt divalent state [32]. In addition, the fact that the hydrogenation potential of cobalt lies between those of nickel (active in methanation) and iron (selective for alkene oxidation) seems to be useful for the selective formation of alkanes of higher molecular weight.

In our previous studies on non-hydrolytic sol-gel processed materials for catalytic applications [33] we had incorporated cobalt into an alumina matrix, CoNHG, and had shown that these materials can be custom-tailored by choosing the temperature employed during the heat treatment. The use of different temperatures throughout this treatment resulted in materials of different compositions and structures, which could influence their catalytic activity.
To continue our studies, we decided to investigate a way to improve the catalytic efficiency and selectivity of the CoNHG system by incorporating silica into the alumina matrix. The present work reports the optimized conditions for the preparation of cobalt entrapped into aluminum silicate materials in the powder form. These materials, designated CoAlSi-NHG, were obtained by a non-hydrolitic sol-gel route via condensation of aluminum chloride with diisopropylether in the presence of cobalt chloride, followed by reaction with tetraethoxysilane (TEOS). The obtained materials were heat-treated at various temperatures $\left(25,400,750,1000\right.$, and $\left.1100{ }^{\circ} \mathrm{C}\right)$ and characterized by ultraviolet visible spectroscopy, X-ray diffraction (XRD), ${ }^{29} \mathrm{Si}$ and ${ }^{27} \mathrm{Al}$ NMR, surface area, thermogravimetric analysis (TGA), differential thermal analysis (DTA), and transmission electron microscopy (TEM). The materials obtained via the different heat treatments were used as catalysts for the oxidation of $(Z)$ cyclooctene, cyclohexane, and $n$-heptane by iodozylbenzene.

\section{Experimental}

All solvents and reagents were of commercial grade (Merck and Aldrich) unless otherwise stated. dichloromethane (DCM) was suspended on anhydrous $\mathrm{CaCl}_{2}$ for $2.5 \mathrm{~h}$, filtered, distilled over $\mathrm{P}_{2} \mathrm{O}_{5}$, and kept over $0.4 \mathrm{~nm}$ molecular sieves. The substrate $(Z)$-cyclooctene was purified on a basic alumina column immediately before use.

\subsection{Entrapment of cobalt chloride into aluminum silicate by a non-hydrolytic sol-gel process (CoAlSi-NHG)}

The preparation of the gels was performed in oven-dried glassware. The solid material was synthesized via modification of the method described by Corriu and co-workers [34]. Aluminum chloride $\left(\mathrm{AlCl}_{3}, 1.0 \mathrm{~mol} \mathrm{~L}{ }^{-1}\right)$ and diisopropyl ether ( $\mathrm{Pr}_{2} \mathrm{O}, 1.5 \mathrm{~mol} \mathrm{~L}^{-1}$ ) were reacted in the presence of cobalt(II) chloride $\left(\mathrm{CoCl}_{2}, 8.7 \times 10^{-6} \mathrm{mols}, 3.5 \mathrm{mg}\right)$, in dry DCM $\left(50 \mathrm{~mL}\right.$, previously distilled) reflux at $110{ }^{\circ} \mathrm{C}$, under argon atmosphere. After $1 \mathrm{~h}$, the resulting material was reacted with TEOS (3 mL). A gel was formed after $4 \mathrm{~h}$ of reaction, and after another $0.5 \mathrm{~h}$, a solid material started to precipitate. After reflux, the mixture was cooled and aged overnight in the mother liquor, at room temperature. The solvent was then removed under vacuum. The solid was washed with several solvents in the following order: DCM, acetonitrile, and methanol. Samples of the solid were then heat-treated at various temperatures: 25 , $400,750,1000$, or $1100{ }^{\circ} \mathrm{C}$, to render the catalysts CoAlSiNHG-25, CoAlSi-NHG-400, CoAlSi-NHG-750, CoAlSiNHG-1000, and CoAlSi-NHG-1100, respectively. The heattreatment consisted in keeping the sample in an oven in air atmosphere, followed by heating at a rate of $30{ }^{\circ} \mathrm{C} / \mathrm{min}$, for $4 \mathrm{~h}$.

Electronic spectra of the CoAlSi-NHG materials were recorded on a Hewlett-Packard 8453, Diode Array UV-vis spectrophotometer. The spectra of the solids in DCM were recorded in a $2.0-\mathrm{mm}$ path length cell. DCM was the solvent of choice because it led to improved UV-vis spectra when the suspension was prepared. The spectra were preprocessed by using wavelets filter 44.45 with the Dubauchie (db4) base 
function for noise minimization, subtraction of the isotonic medium spectrum, multiplicative scattering correction46 (MSC) to minimize Raleigh scattering due to variation in the refraction index for the matrix, and a second degree polynomial fit to minimize matrix fluorescence.

Thermogravimetric analysis (TGA) and differential thermal analysis (DTA) were carried out using a Thermal Analyst TA Instrument SDT Q 600 Simultaneous DTA-TGA-DSC, in nitrogen, at a heating rate of $20{ }^{\circ} \mathrm{C} / \mathrm{min}$, from 25 to $1500{ }^{\circ} \mathrm{C}$.

$X$-ray diffraction patterns were collected on a Siemens model D 5005 diffractometer using $\mathrm{Cu} \mathrm{K} \alpha$ radiation.

${ }^{29} \mathrm{Si} N M R$ and ${ }^{27} \mathrm{Al}(59.5 \mathrm{MHz})$ spectra were obtained with an INOVA 300-Varian spectrophotometer, using rotor silicon nitride as reference. The conditions employed for spectra acquisition were: relaxation delay $=15 \mathrm{~s}$, pulse $=101.2^{\circ}$, acquisition time $=0.050 \mathrm{~s}$, width $=100.0 \mathrm{kHz}$, and total time $=14 \mathrm{~h}$.

Transmission electron microscopy (TEM) was performed using a Phillips CM 200 transmission electron microscope. Specimens for TEM analysis were prepared by grinding the material into finer particles which were subsequently deposited on carbon-coated palladium films supported on 300-mesh capped grids.

Iodosylbenzene (PhIO) was obtained through hydrolysis of iodosylbendenediacetate. Purity was measured by iodometric assay [35,36].

Specific surface areas were determined by analyzing the nitrogen adsorption isotherms according to the BET method [37] using a physical adsorption analyzer (Micrometrics AccSorb 2100E).

\subsection{Oxidation reactions}

Iodosylbenzene $(\sim 0.023 \mathrm{mmol})$ was added to a $4 \mathrm{~mL}$ vial sealed with a teflon-coated silicone septum containing CoAlSiNHG $(10 \mathrm{mg})$; 1,2-dichloroethane $(1000 \mu \mathrm{L})$; $(Z)$-cyclooctene (previously purified on alumina column) or cyclohexane or $n$ heptane as substrate $(\sim 1.15 \mathrm{mmol})$; and internal standard $(5 \mu \mathrm{L})$. The reaction products were analyzed by gas chromatography. These analyses were carried out using an HP 6890 chromatograph equipped with a hydrogen flame ionization detector and capillary column (length $=30 \mathrm{~m}$, internal diameter $=0.25 \mu \mathrm{m})$. Yields were determined by comparison with authentic samples by using calibration curves. Cyclohexanone was used as internal standard for analysis of the reaction products obtained in the oxidation of $(Z)$-cyclooctene, and $n$-octanol was used as internal standard in the case of cyclohexane and $n$-heptane oxidations.

A control of the reactions was carried out in the absence of catalyst (CoAlSi-NHG or homogeneous catalyst $\mathrm{CoCl}_{2}$ ), and in the presence of $\mathrm{AlSi}-\mathrm{NHG}$ without $\mathrm{CoCl}_{2}$.

\section{Results and discussion}

\subsection{Preparation of the CoAlSi-NHG materials}

The CoAlSi-NHG materials were prepared through a nonhydrolytic condensation sol-gel route, by adding the cobalt

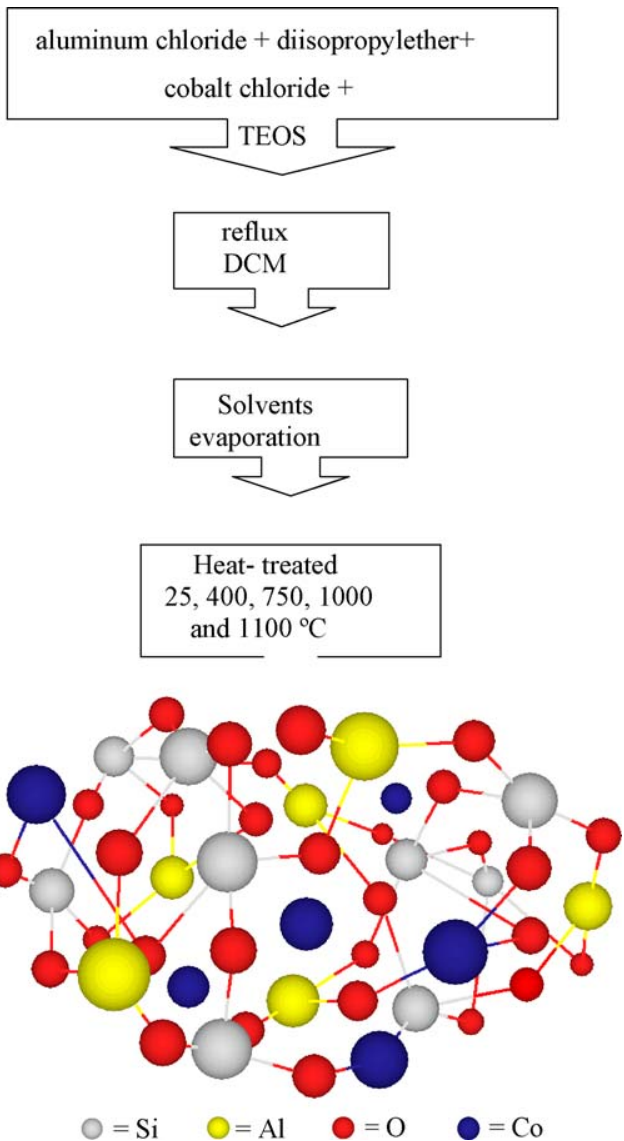

Scheme 1. Preparation of the CoAlSiNHG materials.

ions to a starting solution of $\mathrm{AlCl}_{3}$ in $(\mathrm{iPr})_{2} \mathrm{O}$, followed by addition of TEOS, as outlined in Scheme 1. The non-hydrolytic sol-gel methodology is based on reactions that do not employ water as the oxygen source. Therefore, to ensure the absence of water in the $\mathrm{CoCl}_{2}$ salt employed as the source of cobalt ions, this salt was heat-treated at $300{ }^{\circ} \mathrm{C}$ before cobalt insertion into the aluminum silicate matrix.

The sol-gel method employed herein is based on the condensation of aluminum halides with ether, through the cleavage of the $\mathrm{O}-\mathrm{R}$ bond and formation of an aluminum alkoxide-halide, followed by release of an alkyl halide [3034]. The aluminum alkoxide was produced in situ from aluminum chloride and $i \operatorname{Pr}_{2} \mathrm{O}$ through the formation of a Lewis adduct, followed by a nucleophilic displacement on carbon [30-34]. After the initial formation of the aluminum alkoxidehalide, TEOS was added to the solution. The presence of TEOS in this solution containing the aluminum alkoxide-halide led to a cross-condensation between $\mathrm{Al}$ and $\mathrm{Si}$, with formation of $\mathrm{Al}-$ $\mathrm{O}-\mathrm{Si}$ bridges. Sol gelation was generated from an alkoxidehalide non-hydrolytic self-condensation (formation of Al-O$\mathrm{Al}$ or $\mathrm{Si}-\mathrm{O}-\mathrm{Si}$ bridges) or cross-condensation (Al-O-Si bridges). The condensation reactions did not lead to the perfect formation of $\mathrm{Al}-\mathrm{O}-\mathrm{Si}$ bridges with perfect alternation of the $\mathrm{Al}$ and $\mathrm{Si}$ centers. The homogeneity of the network depends on the relative rates of self-condensation toward cross-condensation. If the self-condensation and cross-condensation rates are of the same order, homogeneity is achieved, 
Table 1

Properties of the CoAlSi-NHG materials heat-treated at various temperatures: $\mathrm{UV}-\mathrm{vis}$ spectra $(\mathrm{nm})$ and coloring

\begin{tabular}{lll}
\hline Sample & UV-vis absorbance $(\mathrm{nm})$ & Colors \\
\hline CoAlSi-NHG-25 & $306,360,391,432,475,525,556,645$ & Blue \\
CoAlSi-NHG-400 & $345,395,431,472,527,557,592,645$ & Black \\
CoAlSi-NHG-750 & $357,393,432,529,560,654$ & Dark blue \\
CoAlSi-NHG-1000 & $345,365,430,472,530,560,644$ & Blue \\
\hline
\end{tabular}

with a random distribution of $\mathrm{Al}-\mathrm{O}-\mathrm{Al}, \mathrm{Si}-\mathrm{O}-\mathrm{Si}$, and $\mathrm{Al}-\mathrm{O}-\mathrm{Si}$ bridges.

The binary gel formed in these reactions contained the cobalt ions confined in its skeleton. Maintaining reflux after gelation gave rise to the precipitation of a powder (CoAlSi$\mathrm{NHG}$ ), and the cobalt complex remained entrapped in the $\mathrm{Al} / \mathrm{Si}$ network. The CoAlSi-NHG powder is blue, which is typical of $\mathrm{Co}^{2+}$ tetrahedral species. Precipitation continued throughout aging in the mother liquor and during solvent removal. The UV-vis spectra of the mother liquor did not display the bands characteristic of the cobalt complex, indicating that this complex was totally entrapped in the CoAlSi-NHG material. Further heat treatment performed at various temperatures (400, 750,1000 , and $1100{ }^{\circ} \mathrm{C}$ ) showed that the color of the materials was dependent on the temperature, as previously observed [33]

\subsection{UV-vis spectroscopy of the CoAlSi-NHG materials}

UV-vis spectroscopy of the heat-treated materials provided information on the oxidation state of the cobalt ion. The UVvis spectra and the color of the solids were found to be dependent on the temperature used in the heat treatment (Table 1). The sample obtained at $25^{\circ} \mathrm{C}$, CoAlSi-NHG-25, exhibited a blue color and its UV-vis spectrum displayed bands in the region between 300 and $400 \mathrm{~nm}$, which is typical of $\mathrm{Co}^{3+}$ octahedral species, as well as a three-band absorption pattern with bands around 543,580, and $630 \mathrm{~nm}$ (Table 1), which is typical of $\mathrm{Co}^{2+}$ ions in tetrahedral coordination. These latter absorptions are due to the following electronic transitions of tetrahedrally coordinated $\mathrm{Co}(\mathrm{II})$ [36]:

$$
\begin{aligned}
& { }^{4} \mathrm{~A}_{2}(\mathrm{~F})\left(\mathrm{e} 4 \mathrm{t}^{3}\right): \mathrm{v}_{1}={ }^{4} \mathrm{~A}_{2}(\mathrm{~F}) \rightarrow{ }^{4} \mathrm{~T}_{2}(\mathrm{~F}): \mathrm{v}_{2} \\
& \quad={ }^{4} \mathrm{~A}_{2}(\mathrm{~F}) \rightarrow{ }^{4} \mathrm{~T}_{1}(\mathrm{~F}) ; \mathrm{v}_{3}={ }^{4} \mathrm{~A}_{2}(\mathrm{~F}) \rightarrow{ }^{4} \mathrm{~T}_{1}(\mathrm{P}) .
\end{aligned}
$$

Bands with similar positions have been reported for cobaltaluminophosphate and cobaltsilicoaluminophosphate, and they have been interpreted as being an evidence of the presence of tetrahedrally coordinated $\mathrm{Co}^{2+}$ in the structure of the aluminophosphate framework [40]. These absorptions are attributed to the ${ }^{4} \mathrm{~A}_{2}-{ }^{4} \mathrm{~T}_{1}(\mathrm{P})$ transition in tetrahedral $\mathrm{Co}^{2+}$, which clearly indicates that $\mathrm{Co}^{2+}$ is present in the framework of these materials in tetrahedral coordination [38-41]. A comparison of our materials with aluminophosphate is inevitable since cobalt-substituted aluminophosphates are the most extensively investigated systems. Moreover, it is reported that the blue color of materials containing cobalt is typical of tetrahedral $\mathrm{Co}^{\mathrm{II}} \mathrm{O}_{4}$ environments, which is consistent with cobalt occupying tetrahedral sites in the framework. The $\mathrm{Co}^{2+}$ ions confer ligand-field stalibility to complexes when they are present in the tetrahedral coordination [42].

The sample heat-treated at $400{ }^{\circ} \mathrm{C}$, CoAlSi-NHG-400, exhibited a black color. Its UV-vis spectrum displayed UVvis bands typical of $\mathrm{Co}^{2+}$ ions in the tetrahedral coordination, as well as bands at 324 and $393 \mathrm{~nm}$, assigned [40] to $\mathrm{Co}^{3+}$ octahedral species formed during the heating treatment. We attributed the color and the UV-vis spectrum of this material to the presence of a mixed-valence oxide, $\mathrm{Co}_{3} \mathrm{O}_{4}$, which consists of a mixture of octahedral $\mathrm{Co}^{3+}\left(\mathrm{e}_{\mathrm{g}} \leftarrow \mathrm{t}_{2 \mathrm{~g}}\right.$ transition) and tetrahedral $\mathrm{Co}^{2+}$ species. Heating the material from 750 to $1100{ }^{\circ} \mathrm{C}$ made it become progressively bright blue. The intensity of the UV-vis bands characteristic of the $\mathrm{Co}^{3+}$ octahedral species at 324 and $393 \mathrm{~nm}$ decreased, while the bands typical of $\mathrm{Co}^{2+}$ in tetrahedral coordination $(540-630 \mathrm{~nm}$ region) increased. These results gave evidence that $\mathrm{Co}^{3+}$ was reduced to $\mathrm{Co}^{2+}$ around $700{ }^{\circ} \mathrm{C}$, and thereafter the material became bright blue and displayed a UV-vis spectrum typical of $\mathrm{Co}^{2+}$ ions in tetrahedral coordination. The same dependence of the cobalt oxidation state and of the color of the material on the heat treatment pattern had been observed in the case of $\mathrm{CoAl}_{2} \mathrm{O}_{4}$ materials prepared by the sol-gel process [33], showing that the $\mathrm{Co}^{3+}$ ions present in the starting material were reduced to $\mathrm{Co}^{2+}$, and that heating plays an important role in cobalt incorporation into the aluminosilicate framework.

\subsection{Surface area of the CoAlSi-NHG materials}

The porosity and surface properties of the materials were determined using nitrogen adsorption according to the BET method [37], and results are summarized in Table 2. The fine nature of the materials can be observed in this table and is an indication that the materials prepared in this work can be used as pigments for most of the purposes.

Table 2 shows that the CoAlSi-NHG materials have low surface area, between 3 and $53 \mathrm{~m}^{2} \mathrm{~g}^{-1}$, and large pore size diameter. The pore size distribution of the heat-treated materials lay between 38 and $147 \mathrm{~nm}$ (Table 2) and depended on the temperature that the material was submitted to throughout the heat-treatment, as previously observed for the cobalt silicates obtained by us [33] and others [43]. The BET results (Table 2) suggest that the surface area and porosity decreased with increasing heating temperature. As soon as material crystallization began at $750{ }^{\circ} \mathrm{C}$, as revealed in the corresponding X-ray diffractograms in Fig. 1, its surface area started to decrease. In this kind of material, higher crystallinity is associated with lower surface area. In fact, the material remained amorphous up to a

Table 2

Structural properties of CoAlSi-NHGs, heat-treated at different temperatures

\begin{tabular}{lclc}
\hline Sample & $\begin{array}{l}\text { BET specific } \\
\text { surface area } \\
\left(\mathrm{m}^{2} \mathrm{~g}^{-1}\right)\end{array}$ & $\begin{array}{l}\text { Pore volume } \\
\left(\mathrm{cm}^{3} \mathrm{~g}^{-1}\right)\end{array}$ & $\begin{array}{l}\text { Pore size } \\
\text { diameter } \\
(\mathrm{nm})\end{array}$ \\
\hline CoAlSi-NHG-25 & 3 & 0.0090 & 147 \\
CoAlSi-NHG-400 & 53 & 0.050 & 37 \\
CoAlSi-NHG-750 & 10 & 0.029 & 111 \\
CoAlSi-NHG-1100 & 9 & 0.026 & 127 \\
\hline
\end{tabular}




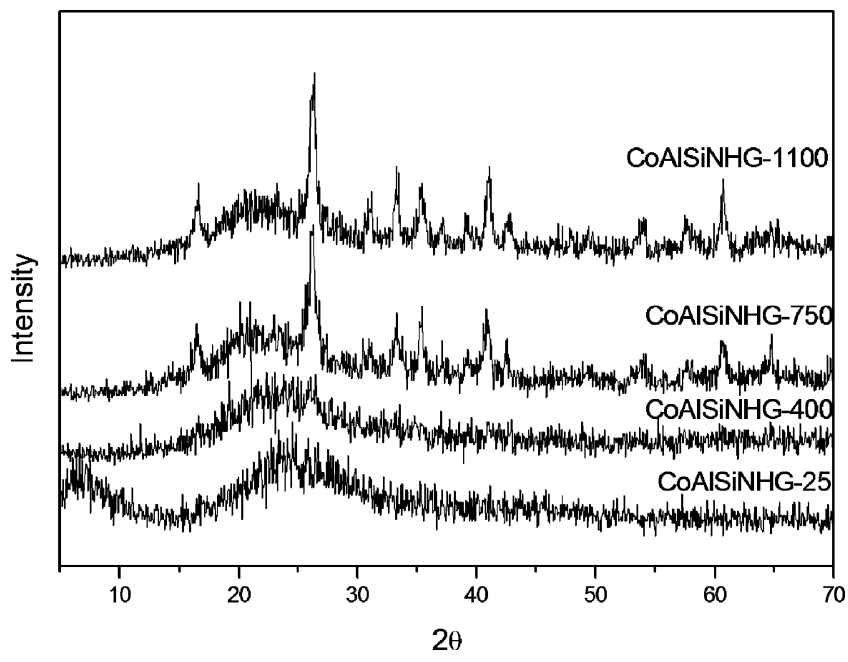

Fig. 1. X-ray powder diffraction patterns of the CoAlSi-NHG samples.

temperature of $400{ }^{\circ} \mathrm{C}$, and a larger surface area was obtained in the case of CoAlSi-NHG-400.

The low surface area and porosity observed in the case of CoAlSi-NHG-25 can be explained by the fact that there still exists adsorbed species in the material at $25{ }^{\circ} \mathrm{C}$, which leaves extra space within the pores and leads to very low porosity. The large pore size diameter obtained in this case is in agreement with this observation.

\subsection{X-ray diffraction of the CoAlSi-NHG materials}

The X-ray powder diffraction patterns of the CoAlSi-NHG samples indicate that these materials remained amorphous when temperatures as high as $750{ }^{\circ} \mathrm{C}$ were used in the heat treatment (Fig. 1). At $1000{ }^{\circ} \mathrm{C}$, an evidence of crystallization was observed in the XRD, indicating that crystallization took place during the heating process.

The XRD-peaks of the material heated-treated at $1100{ }^{\circ} \mathrm{C}$ show that it was not fully crystallized. The most intense peak at $2 \theta=26.5^{\circ}$ is indicative of mullite, $3 \mathrm{Al}_{2} \mathrm{O}_{3} \cdot 2 \mathrm{SiO}_{2}[44,45]$.

Mullite is the only stable phase in the $\mathrm{Al}_{2} \mathrm{O}_{3}-\mathrm{SiO}_{2}$ binary system. Due to its excellent physical and mechanical properties at high temperatures, such as high melting point, low thermal expansion, good resistance to fracture and to thermal shock, high creep resistance, thermal stability, low density, and low dielectric constant, it has become widely used in ceramic bodies. However, mineral mullite is rare and almost nonexistent in nature, so it is desirable that the mullite phase is obtained in synthetic aluminosilicates [45].

Diffraction peaks observed for the material heat-treated at $1100{ }^{\circ} \mathrm{C}$ correspond to mullite, according to the CAS card number 15-0776. The diffraction peaks of $\gamma$-alumina at $2 \theta=43^{\circ}$ were also found for the materials heat-treated at 1000 and $1100{ }^{\circ} \mathrm{C}[44,45]$.

It is interesting that the solid-solid transformation of amorphous aluminum silicate xerogels into crystalline mullite occurs only because of the heat-treatment, dismissing the addition of soluble silicate or aluminate molecules, as previously reported for zeolite materials [46].

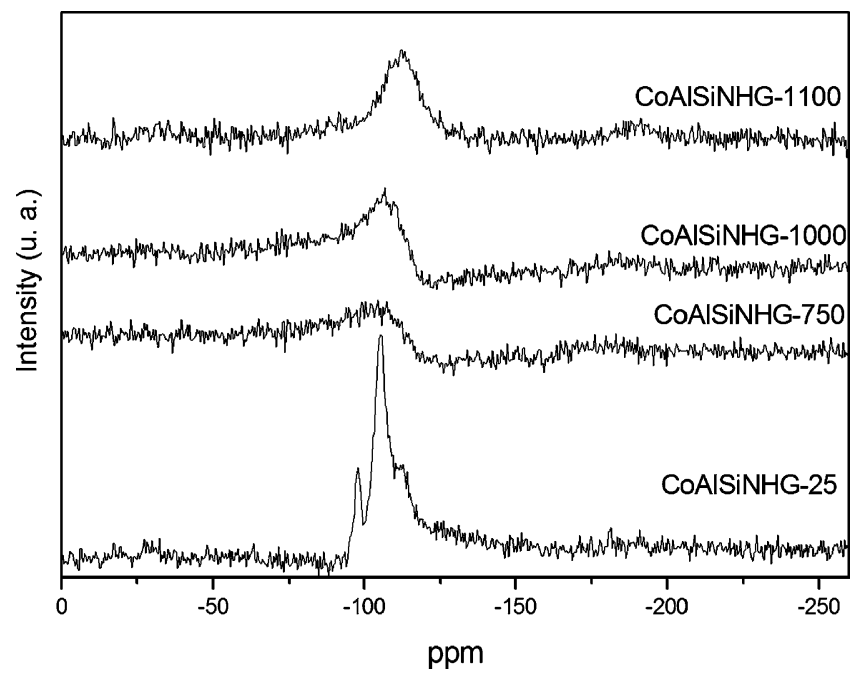

Fig. 2. ${ }^{29} \mathrm{Si}$ NMR spectrum of the CoAlSi-NHG samples.

The presence of crystalline silica was not observed in these materials at any temperature. As expected, when we compared the material heated-treated at $1100{ }^{\circ} \mathrm{C}$ with the material prepared without the cobalt ions (blank), we observed that there was no extra peak due to the presence of cobalt; the peak positions were identical to those found in the XRD of the blank. This could be due to the presence of very low concentrations of cobalt in the framework.

\subsection{NMR of the CoAlSi-NHG materials}

The local structure of the aluminum silicate was studied using solid-state NMR. The silicon and aluminum spectra are shown in Figs. 2 and 3, respectively.

The ${ }^{29} \mathrm{Si}$ NMR spectrum of the sample obtained at room temperature (Fig. 2) displayed peaks typical of amorphous silica, which is in agreement with the XRD results. Two different silicons with different degrees of condensation could be present in the materials, Q4 (-106 ppm) and Q3 (-97 ppm). The feature at $-106 \mathrm{ppm}$ may be attributed to a silica-rich

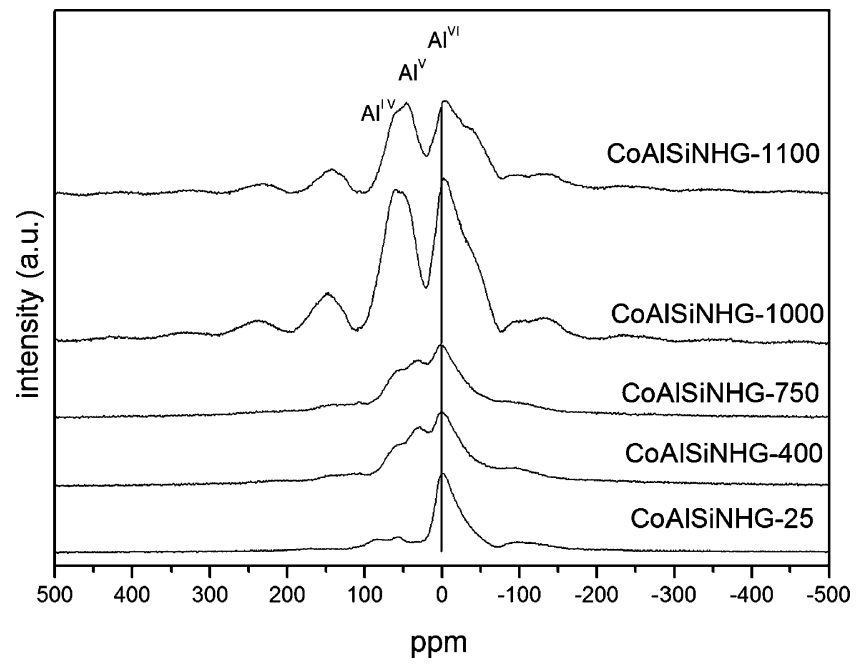

Fig. $3 .{ }^{27} \mathrm{Al}$ NMR spectrum of the CoAlSi-NHG samples. 
phase, $\mathrm{Si}\left[(\mathrm{OSi})_{4}\right]$, and the peak at $-97 \mathrm{ppm}$ could correspond to $\mathrm{Si}(\mathrm{OSi})_{3} \mathrm{OH}$ sites [47]. At $750{ }^{\circ} \mathrm{C}$, the spectrum displayed a broad distribution of silicon sites at $-105 \mathrm{ppm}$, characteristic of a mixture of aluminum and silicon with the formation of $\mathrm{Si}-\mathrm{O}-$ $\mathrm{Al}$ bonding. This signal corresponds to the overlap of the five possible tetrahedral silicon environments [47]. In fact, Gerardin et al. [44] have attributed this signal at $-105 \mathrm{ppm}$ to amorphous aluminum silicate structures displaying a random distribution of silicon and aluminum.

The ${ }^{29} \mathrm{Si}$ NMR spectrum of the materials heat-treated at temperatures higher than $750{ }^{\circ} \mathrm{C}$ displayed a broad signal around $-106 \mathrm{ppm}$, characteristic of amorphous silicon with a high degree of hydrolysis (Q4). The shoulder at $-102 \mathrm{ppm}$ is typical of $\mathrm{Si}(\mathrm{OAl})(\mathrm{OSi})_{3}$ [47]. Small peaks at -87 and $-93 \mathrm{ppm}$ could be an indication of the formation of mullite. The presence of the broad peaks shows that complete crystallization of the materials did not occur, as observed by XRD.

The ${ }^{27} \mathrm{Al}$ NMR spectrum of the material obtained at room temperature displayed three distinct sites at 0,50 , and $83 \mathrm{ppm}$, corresponding to the presence of octahedral (hexacoordinated) and tetrahedral aluminum in the aluminum silicate, respectively. The octahedral species strongly prevailed. For the samples heat-treated at 400 and $750{ }^{\circ} \mathrm{C}$, the most pronounced peak at $0 \mathrm{ppm}$ corresponds to octahedral aluminum. The peak at $30 \mathrm{ppm}$ was assigned to pentacoordinate Al [48], and the shoulder at $64 \mathrm{ppm}$ was attributed to tetrahedral Al.

The presence of the peaks corresponding to tetrahedral aluminum indicates that there was formation of an aluminum silicate, as observed by the ${ }^{29} \mathrm{Si} \mathrm{NMR}$ spectra. It is expected that aluminum should adopt a tetrahedral coordination to four silicons via oxygen bridges when it is incorporated into a silicate framework. Non-incorporated aluminum should form a typical aluminate with octahedral coordination. So the fact that the peak corresponding to octahedron aluminum prevailed at room temperature, as well as at 400 and $750{ }^{\circ} \mathrm{C}$ can be explained by the presence of excess aluminum in the samples.

As already reported by Curriu et al. [20-25] and observed by our group in the case of aluminates [33], material heating at temperatures above $750{ }^{\circ} \mathrm{C}$ led to the disappearance of the peaks corresponding to pentacoordinated aluminum. In the case of the samples heat-treated at 1000 and $1100{ }^{\circ} \mathrm{C}$, we observed that the peak typical of tetrahedral aluminum increased, which indicates that the heat treatment enhanced the formation of aluminum silicates. Another explanation for the presence of peaks corresponding to tetrahedral coordination is the formation of mullite.

\subsection{TGA-DTA analysis of the CoAlSi-NHG materials}

The TGA-DTA data of the CoAlSi-NHG materials measured at different stages of the thermal treatment are shown in Fig. 4. The samples underwent an endothermic transition at $125^{\circ} \mathrm{C}$, corresponding to the loss of water molecules weakly bound to the materials. An exothermic broad peak at $475{ }^{\circ} \mathrm{C}$ corresponding to the pyrolysis and the oxidation of residual alkyl halide groups could also be seen. Differential thermal analysis indicated that there were two exothermic

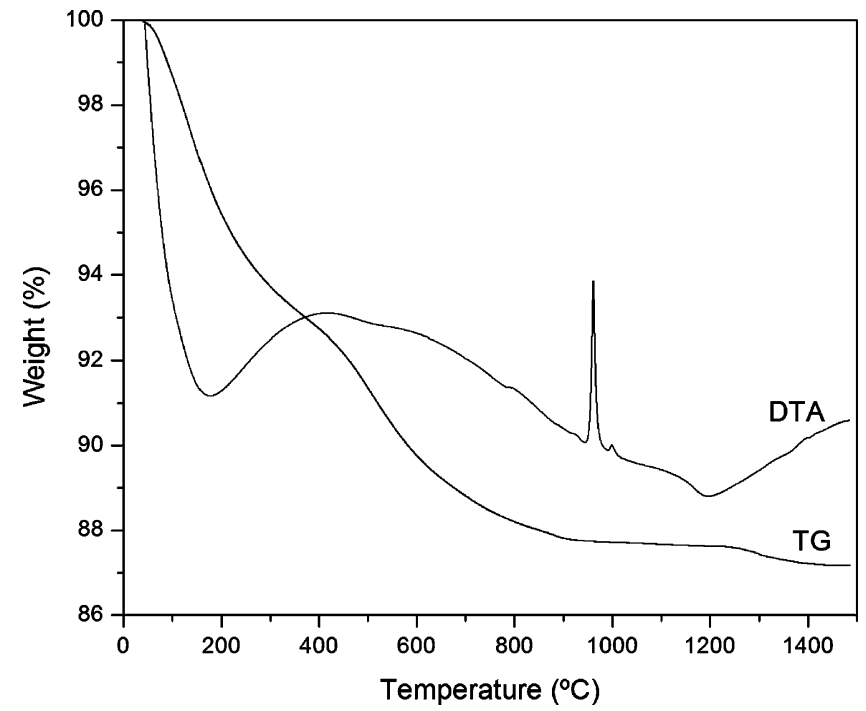

Fig. 4. TGA and DTA in air of CoAlSi-NHG.

transformations, at 920 and $960{ }^{\circ} \mathrm{C}$, in a region where no weight loss was observed by TGA. These two exothermic transformations at 920 and $960{ }^{\circ} \mathrm{C}$ were ascribed to the appearance of a more ordered alumina transition phase and to material crystallization, respectively. Many works in the literature have attributed the exothermic peak at $980{ }^{\circ} \mathrm{C}$ to the crystallization of mullite and/or spinel. Gerardin et al. [44] has reported many results showing that the existence of an exothermic peak at $980{ }^{\circ} \mathrm{C}$ is related to the transformation of pentacoordinated aluminum atoms into more stable tetrahedrally and octahedrally coordinated ions. Another work has stated that the peak at $980^{\circ} \mathrm{C}$ is due to the presence of mullite with tetragonal symmetry and a composition with a higher ratio of $\mathrm{Al}_{2} \mathrm{O}_{3}$.

\subsection{TEM of the CoAlSi-NHG materials}

TEM bright-field images and selected-area electron diffraction patterns of the CoAlSi-NHG materials heat-treated at different temperatures are shown in Fig. 5. The micrograph of the CoAlSi-NHG samples show, in agreement with the XRD pattern presented previously, that sample crystallization occurs with increasing temperature. At $1100{ }^{\circ} \mathrm{C}$, the material was crystalline and not yet fully dense. The crystalline entities detected in the CoAlSi-NHG-1100, grew directly from the amorphous solid phase through a process of aggregation and densification.

\subsection{Catalytic reactions}

Aluminum silicates are widely used in catalytic processes, such as the cracking of petroleum fractions, and elucidation of their structures and surface properties provides exciting challenges for scientists. Therefore, we decided to investigate the catalytic properties of CoAlSi-NHG in oxidation reactions.

In order to check the catalytic activity of the catalysts prepared in this paper, the diagnostic substrate $(Z)$-cyclooctene was submitted to oxidation by $\mathrm{PhIO}$ in the presence of CoAlSiNHG, at room temperature and pressure. (Z)-Cyclooctene is a 


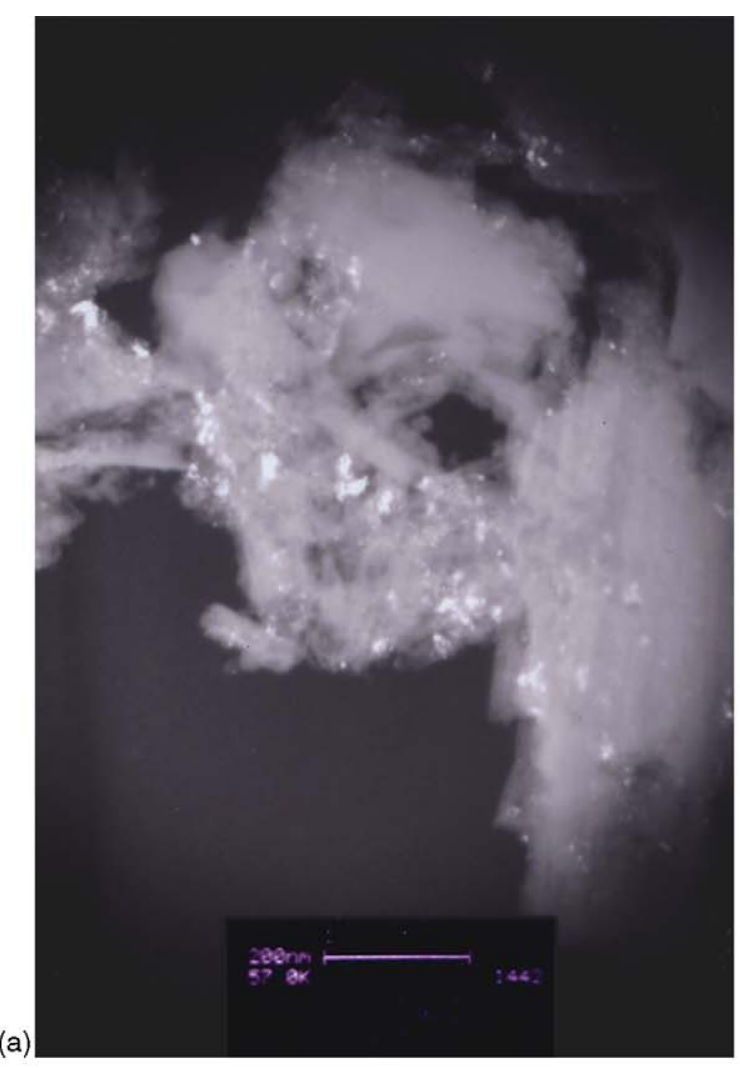

(b)
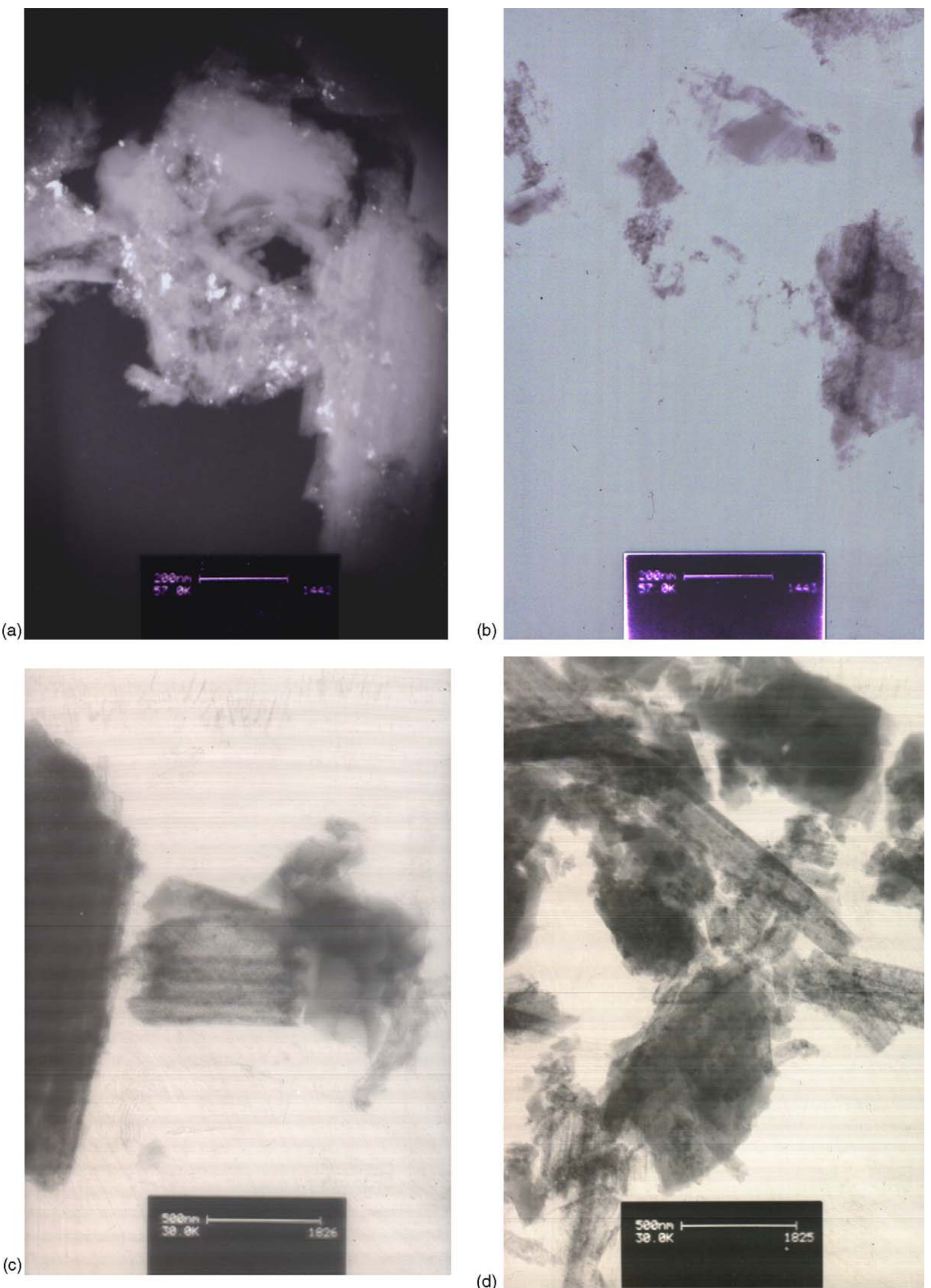

Fig. 5. Micrographs of the material heat-treated at different temperatures: (a) dark field at $750{ }^{\circ} \mathrm{C}$; (b) bright field at $750{ }^{\circ} \mathrm{C}$; (c) bright field at $1000{ }^{\circ} \mathrm{C}$; (d) bright field at $1000{ }^{\circ} \mathrm{C}$; (e) electron diffraction at $1100{ }^{\circ} \mathrm{C}$; (f) bright field at $1100{ }^{\circ} \mathrm{C} ;(\mathrm{g})$ dark field at $1100{ }^{\circ} \mathrm{C}$. 

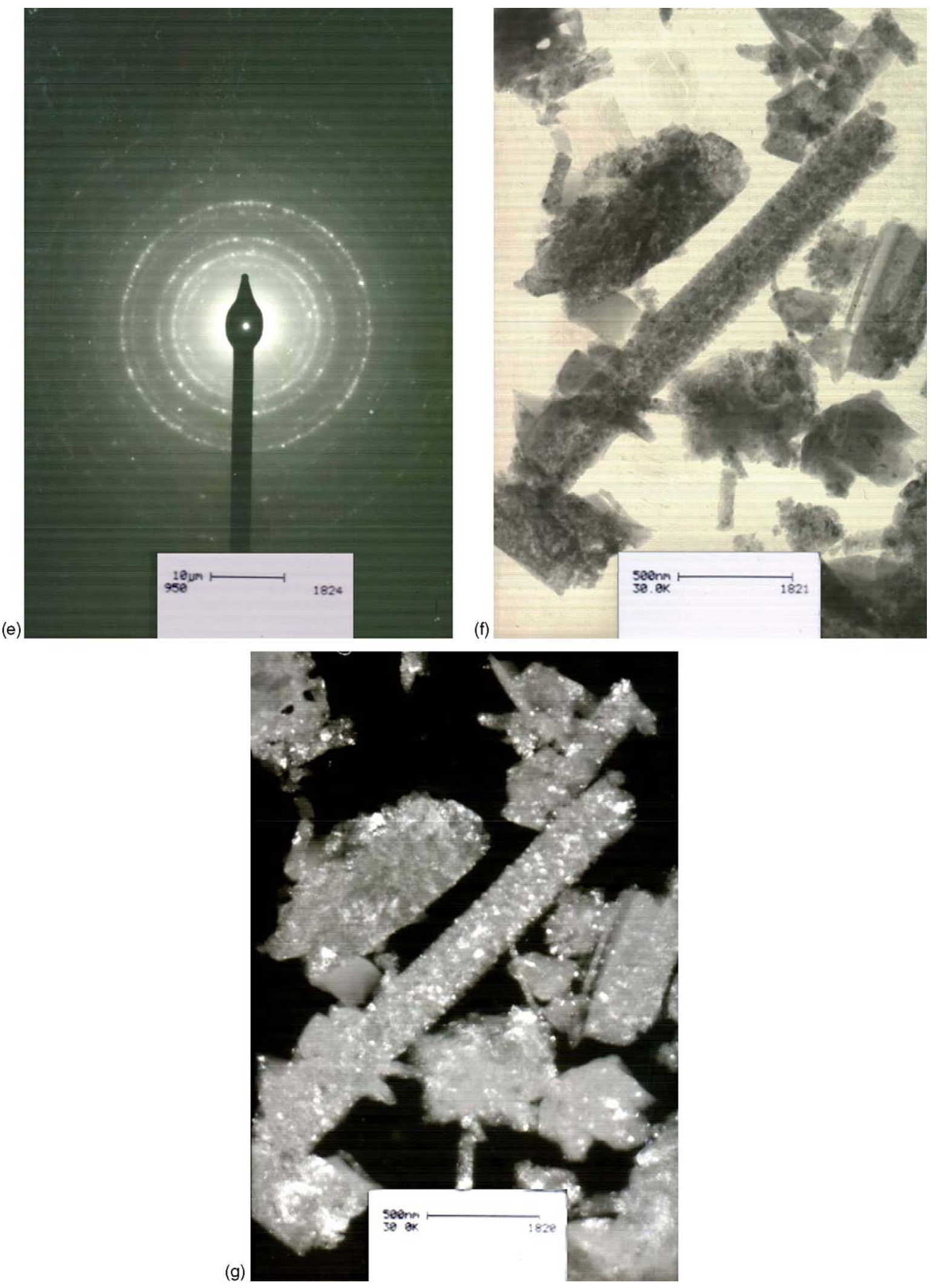

Fig. 5. (Continued).

reactive alkene that has been used with both homogeneous and heterogeneous catalysts in previous studies, and ( $Z$ )-cyclooctene oxide results as the main reaction product. $\mathrm{PhIO}$ was chosen as oxygen source because it can give good oxidant conversion and is relatively inert in the absence of a catalyst. Moreover, various works in the literature have used the olefin/ iodosylbenzene system, making the use of this system by us useful for comparison purposes. As emphasized by Koola and 
Kochi [49], the use of iodosylbenzene as oxidant is reminiscent of catalytic epoxidations induced by synthetic metalloporphyrins, where the use of this oxidant as oxygen donor was introduced in order to mimic the chemistry of cytochrome P450. As recently stated by Groves [50], the choice of using this oxidant stems from the fact that iodosylbenzene is a polymeric solid that does not contain a weak $\mathrm{O}-\mathrm{H}$ bond, thus eliminating the occurrence of free radical chain reactions normally initiated by oxidants like alkyl hydroperoxides R-O-O-H [50].

Reaction controls were carried out in the absence of cobalt and in the absence of oxidant (separately), and they did not lead to any product yields. The overall oxidant accountability was achieved by measuring the iodobenzene $(\mathrm{PhI})$ yield in all the reactions. Data relative to the $\mathrm{CoCl}_{2}$ in 1,2-dichlorometane homogeneous solution are also presented for comparison and the homogeneous $\mathrm{CoCl}_{2}$ catalysts has been designated $\mathrm{CoCl}_{2}$ in this paper.

All the prepared CoAlSi-NHG materials catalyzed $(Z)$ cyclooctene epoxidation using $\mathrm{PhIO}$ as the oxygen donor (Fig. 6).

The UV-vis spectra of the supernatant solutions obtained after the oxidation reactions showed that there was no catalyst leaching from the support in any of the conditions studied, once the typical cobalt bands were not detected. To prove that catalysis was genuinely heterogeneous and to show the importance of the presence of cobalt in the reactions, the solid catalyst was filtered off the reaction mixture, extra oxidant was added to the resulting supernatant, and the oxidation reaction was allowed to proceed under the same initial conditions for another $24 \mathrm{~h}$. After this period, no cyclooctene oxide was detected, indicating that the catalytic activity of the CoAlSi-NHG materials had been really heterogeneous and that cobalt played an essential role in the catalysis. But it is essential to point out that, as observed by Tilley and co-workers [51] for titania-silica catalysts, we cannot rule out the possibility that catalytically inactive species leached into solution.

From Fig. 6 it can be seen that the catalytic yields obtained with all the CoAlSiNHGs are higher than those obtained with

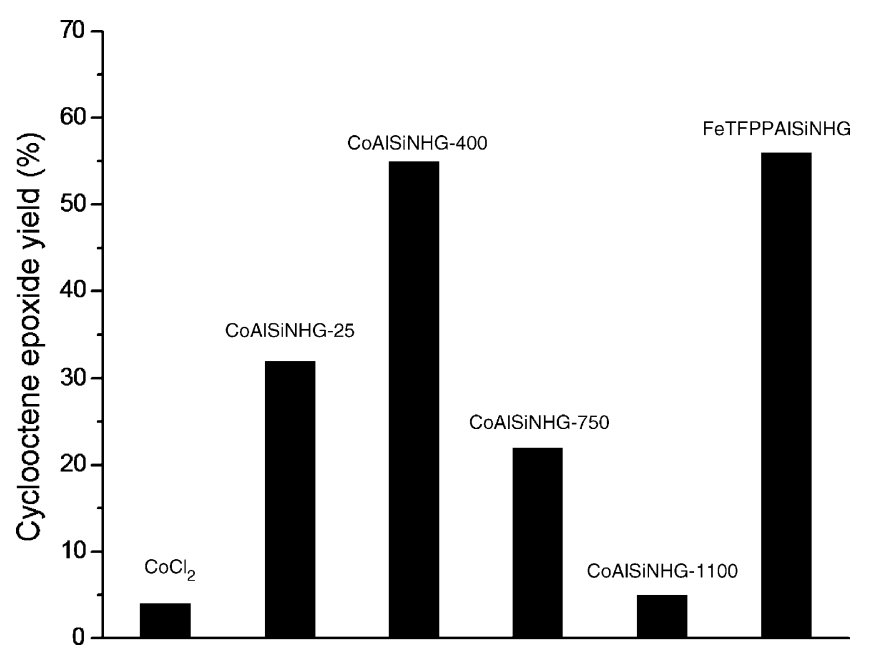

Fig. 6. Catalytic activity of the homogeneous catalyst $\mathrm{CoCl}_{2}$ and CoAlSiNHGs heat-treated at different temperatures in the oxidation of $(Z)$-cyclooctene using $\mathrm{PhIO}$ as oxygen donor. the homogeneous cobalt catalyst. The CoAlSi-NHG-400 material, which presented the largest surface area and the largest pore volume, exhibited the highest activity for the production of cyclooctene epoxide. We attributed this result to two main factors: (i) the larger surface area and pore size of this catalyst may have facilitated the access of the substrate to the cobalt active site in the CoAlSi-NHG-400 catalyst if compared with the catalysts obtained at the different heat-treatments; (ii) as discussed previously in the UV-vis session, the calcination temperatures influence the oxidation state of the cobalt ion. In the particular case of the sample heat-treated at $400{ }^{\circ} \mathrm{C}$, octahedral $\mathrm{Co}^{3+}$ and tetrahedral $\mathrm{Co}^{2+}$ species coexist, which must make the CoAlSi-NHG-400 material a better catalyst than the other CoAlSiNHG catalysts where tetrahedral $\mathrm{Co}^{2+}$ exists alone. A similar behavior was reported for cobaltaluminophosphate, and it was interpreted as evidence of the presence of $\mathrm{Co}^{3+}$ ions in the structure of the latter material [16].

Once it is expected that $\mathrm{Co}^{3+}$ ions (a hard Lewis acid [52]) should have high affinity for oxygen (a hard Lewis base [52]). As for the CoAlSi-NHG-25 catalyst, the catalytic yield was lower, despite the presence of $\mathrm{Co}^{3+}$ ions. According to data presented in Table 2 and to the discussion in the UV-vis section of the present work, CoAlSi-NHG-25 has reduced surface area, making substrate access to the cobalt active site difficult, which results in lower catalytic yields.

It can also be seen when we compared Figs. 1 and 6 that the amorphous systems were more efficient than the crystalline ones, and that the mullite obtained in the CoAlSi-NHG-1100 material did not exhibit great catalytic potential for epoxidation reactions, despite its technological applicability.

Even though cobalt complexes are included among the most widely employed catalysts for the oxidation of different types of organic substrates, and despite its extensive use in industrial oxidations, little is known about the catalytically active cobalt species and how they carry out their function. Studies have demonstrated that the high valent oxo-metal species could be involved in oxidation reactions that employ iodosylbenzene as oxidant $[53,53]$.

The highly reactive oxo-cobalt(IV) species is analogous to the oxo-iron(V) species usually proposed for ironporphyrins (FePs) when they act as cytochrome P450 models. Several studies involving oxidation reactions by $\mathrm{PhIO}$ in the presence of metalloporphyrins have provided a consensus mechanism where PhIO transfers an oxygen atom with two oxidizing equivalents, to form a high valent oxo-iron complex capable of epoxidizing olefins. In the case of FePs, the oxo-iron complex contains a ferryl iron and a porphyrin radical cation [50,54], as represented in Eq. (1).

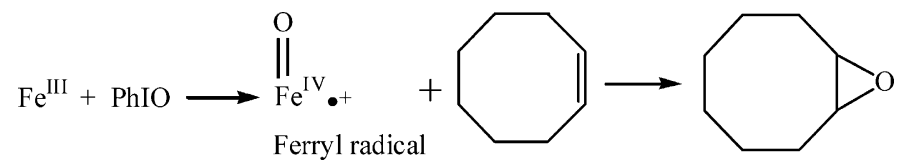

Because all the knowledge concerning the oxo-metal active species was gained from studies of enzymatic models, especially those using synthetic metalloporphyrins, we have included 
results obtained with the second-generation FeP iron(III) mesotetrakis(pentafluorophenylporphyrin) $[\mathrm{Fe}(\mathrm{TFPP})]^{+}$in Fig. 6. This FeP was chosen for comparison purposes because it is one of the most efficient and most widely used catalysts for biomimetic oxidations reactions, besides the fact that ironporphyrins are known to be more efficient catalysts than cobaltporphyrins.

Results presented in Fig. 6 show that the catalytic activity of the CoAlSi-NHG-400 material is similar to that of [Fe(TFPP) $]^{+}$, which is a very good result since it is cheaper to obtain CoAlSiNHG materials than to synthesize an FeP, not to mention the fact that the former catalysts are usually more resistant than the latter, which can undergo degradation in the face of inert substrates. The fact that CoAlSi-NHG-400 and FeAlSiNHG led to similar epoxide yields indicates that oxygen transfer from the oxidant to the alkene may occur via the same mechanism in both cases. Therefore, one may assume that the high valent oxo-metal species $\mathrm{Co}^{\mathrm{IV}}=\mathrm{O}$ is most probably the active species in this transfer, as previously discussed by Koola and Kochi [49] and others [53] and represented in the scheme below (Eq. (2)). The mechanism of $(Z)$-cyclooctene epoxidation occurs in two steps: in the first one, the $\mathrm{Co}^{\mathrm{IV}}=\mathrm{O}$ species is formed via a two-electron oxidation of the tetrahedral $\mathrm{Co}^{2+}$ ions or a one-electron oxidation of octahedral $\mathrm{Co}^{3+}$ ions by iodosylbenzene; in the second step, the $\mathrm{Co}^{\mathrm{IV}}=\mathrm{O}$ species transfer the oxygen atom to the epoxide carbon-carbon double bond, thus forming the epoxide.
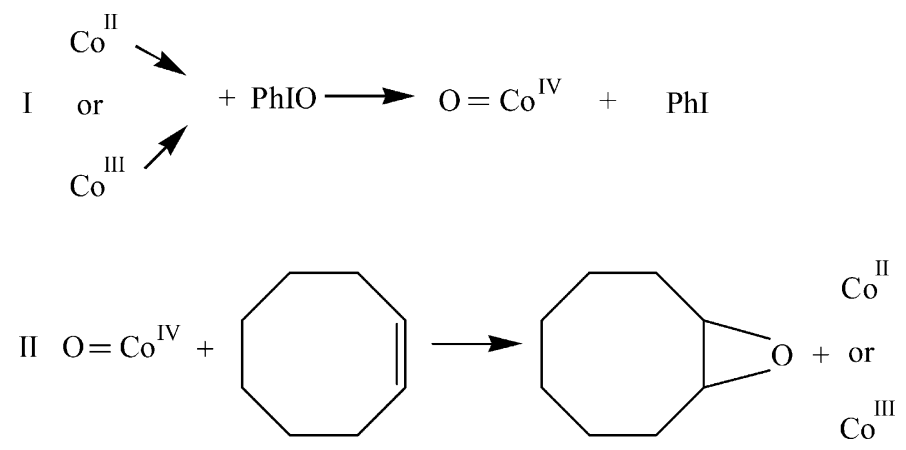

High-valent oxo-cobalt species are generally highly unstable and short-lived. However, we believe that in the case of the CoAlSiNHG materials, the presence of the aluminosilicate matrix mimics the isolated site principle of biological systems, thus stabilizing the oxo-cobalt species long enough for oxygen transfer to take place.

The (Z)-cyclooctene epoxidation reactions were not carried out under inert atmosphere, so oxygen and alkenes in the presence of $\mathrm{Co}^{3+}$ ions could have generated free radicals. To find out whether the oxidizing species generated from the reaction between the CoAlSi-NHG materials and PhIO was distinct from the radicalar species normally detected in systems that do not involve an oxo-metal species, we carried out the $(Z)$ cyclooctene epoxidation reactions again, in the presence of the tert-butyl alcohol radical. This radical scavenger [55,56] did not diminish the product yields, so the involvement of the radical species as the epoxidizing agent could be ruled out. As reported by Koola and Kochi [49], insensitivity to the radical scavenger is understandable since free radicals as such are not the viable intermediates in the catalytic cycle involving the oxometal species and cobalt.

Because (Z)-cyclooctene epoxidation reactions are fast, it is difficult to know for sure which active species is present in the reaction medium. Therefore, we decided to test the performance of the CoAlSiNHG materials as catalysts for cyclohexane and 1-heptane oxidation as well. Cyclohexane was chosen for these studies since it is relatively inert and well reported in the literature, enabling the comparison of our results with those of other authors. This substrate also makes the evaluation of catalyst selectivity possible because it can give cyclohexanol and/or cyclohexanone as oxidation products [16,52,53]. Another reason for studying cyclohexane oxidation is its great industrial importance; its selective oxidation into a mixture of cyclohexanol and cyclohexanone (called K-oil) is employed in the synthesis of textile fibres, such as nylon- 6 and nylon-6.6 [16]. However, the industrial reaction that leads to the oxidized products employs soluble $\mathrm{Co}$ (II) salts as catalyst, molecular oxygen as oxidant, and high temperatures $\left(\sim 160{ }^{\circ} \mathrm{C}\right)$ and pressures (15 bar). In these conditions, only $4 \%$ cyclohexane conversion with $80 \%$ selectivity is obtained, with a cyclohexanol:cyclohexanone molar ratio of $2: 1$. The remaining $20 \%$ consist of by-products [32]. Although the oxidant used in this system is cheap, it is only efficient at temperatures around $70{ }^{\circ} \mathrm{C}$. Therefore, the search for catalysts that are efficient at mild temperatures is a great challenge for both researchers and industries, as emphasized by Schuchardt et al. [11,57].

Results obtained in the cyclohexane oxidation reactions using the various cobalt catalysts prepared in this work are shown in Fig. 7. All the CoAlSiNHG materials catalyzed the oxidation of the cyclohexane saturated $\mathrm{C}-\mathrm{H}$ bonds, leading to $100 \%$ selectivity toward cyclohexanol and cyclohexanone. No other by-product was detected. Fig. 7 also shows that the CoAlSiNHG materials were significantly more selective when compared with the $\mathrm{CoCl}_{2}$ salt.

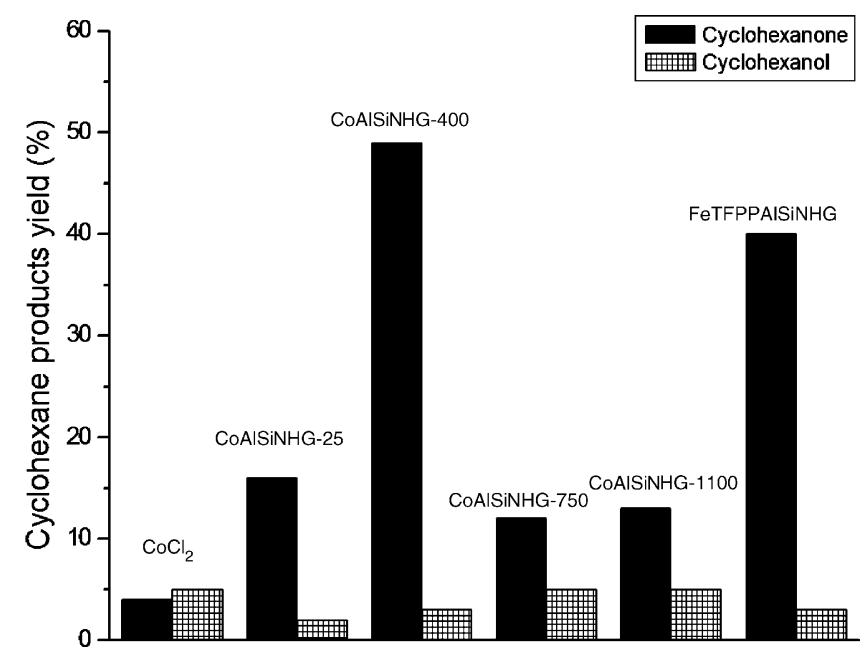

Fig. 7. Catalytic activity of the homogeneous catalyst $\mathrm{CoCl}_{2}$ and CoAlSiNHGs heat-treated at different temperatures in the oxidation of cyclohexane using $\mathrm{PhIO}$ as oxygen donor. 
As in the case of (Z)-cyclooctene epoxidation, no cobalt ion leaching from the support occurred and no reaction product was formed in the absence of cobalt, which shows that this metal ion plays an important role in mediating oxygen transfer from the oxidant to the substrate.

In agreement with results published in the literature [49], it can be seen from Fig. 7 that the catalytic cyclohexane oxidation afforded cyclohexanone as the main product, being only small amounts of cyclohexanol obtained. A control experiment employing FeTFPP entrapped in an aluminosilicate matrix led to the same result; that is, higher selectivity toward cyclohexanone.

As observed in the case of $(Z)$-cyclooctene oxidation, the best product yield and the highest selectivity for cyclohexanone (cyclohexanol 3\% and cyclohexanone 49\%) were obtained with CoAlSi-NHG-400, the catalyst with the highest surface area.

As previously observed by Lindsay with systems employing metalloporphyrins, and by Koola and Kochi [49] and Thomas et al. [16] with matrices containing cobalt, cyclohexanol was readily converted into cyclohexanone in the presence of cobalt ions as catalysts. Actually, aluminosilicate, like zeolites and aluminophosphates, favors rapid formation of cyclohexanol, which later undergoes overoxidation. We confirmed that cyclohexanone was formed from cyclohexanol oxidation (Eq. (3)) in the case of CoAlSiNHGs by observing that when the oxidation reaction was carried out using this alcohol as substrate there was formation of cyclohexanone in significant amounts, for all the prepared catalysts (Fig. 8).

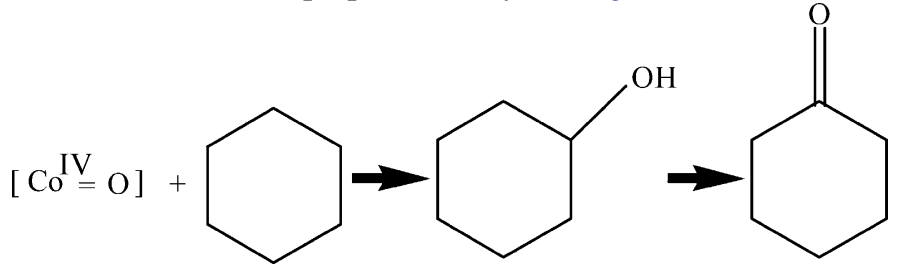

As in the case of $(Z)$-cyclooctene epoxidation, we carried out the reactions in Fig. 7 again in the presence of the tert-butyl

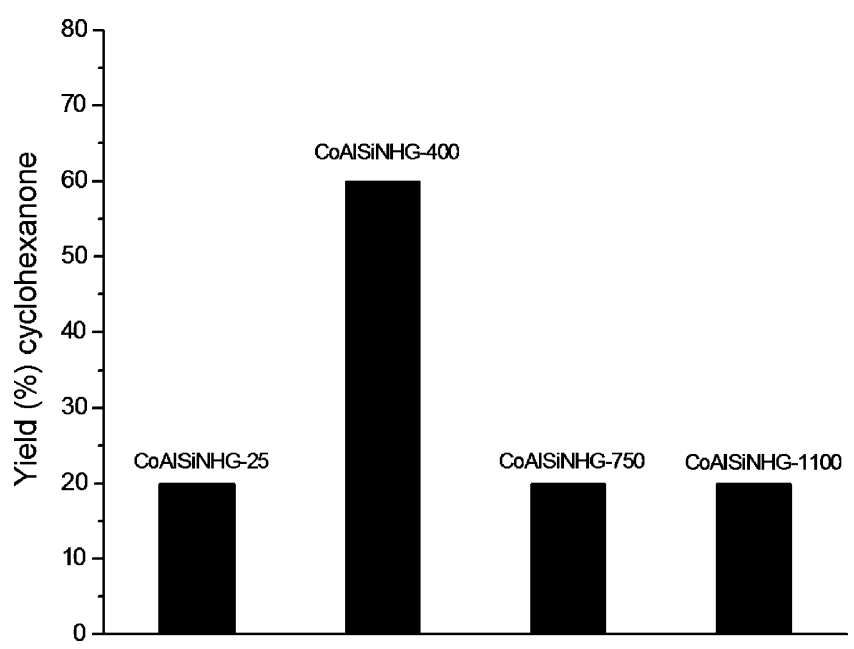

Fig. 8. Catalytic activity of CoAlSi-NHGs heat-treated at different temperatures in the oxidation of cyclohexanol using $\mathrm{PhIO}$ as oxygen donor. alcohol radical. This radical scavenger did not diminish the product yields, so the involvement of radical species as the oxidant agent was to be ruled out.

To verify the type of mechanism involved in the CoAlSiNHG systems using cyclohexane as substrate, another reaction was carried out in the presence of air, but in the absence of PhIO. No detectable cyclohexanol or cyclohexanone yields were obtained in this case. Moreover, we performed the reaction with the most efficient catalyst CoAlSi-NHG-400 also in the absence of air (inert atmosphere), and the results were the same as those obtained in the presence of air.

In view of the versatile nature of the CoAlSi-NHG catalysts, we propose that the oxidations mediated by these catalysts follow the mechanism described above in the oxidation of the $(Z)$-cyclooctene, as in the case of cytochrome P450. After reaction of the cobalt ion with $\mathrm{PhIO}$, the oxo-Co(IV) species must be generated, and this intermediate should be responsible for oxygen atom transfer to the hydrocarbon $\mathrm{C}-\mathrm{H}$ bonds. Formation of this oxo-cobalt species is in agreement not only with results obtained for the CoAlSi-NHG-400 system (Fig. 7) which contains a mixture of $\mathrm{Co}^{2+}$ and $\mathrm{Co}^{3+}$ ions, but also with results of the CoAlSi-NHG-750 and CoAlSi-NHG-1100 catalysts, where $\mathrm{Co}^{2+}$ ions prevail. $\mathrm{Co}^{2+}$ ions, considered to be borderline Lewis acids, have moderate affinity for oxygen atoms, which are hard Lewis bases. Therefore, one would not expect the obtention of significant catalytic results with these materials. So both the efficiency and selectivity obtained with the CoAlSiNHG systems support mechanism presented above.

We decided to also use $n$-heptane as substrate because it is hard to achieve selectivity in the case of $n$-alkanes [58] due to the various $\mathrm{C}-\mathrm{H}$ bonds present in these molecules [18]. The prevalence of thermodynamic factors may occur during oxidation of their $\mathrm{C}-\mathrm{H}$ bonds, which is difficult to control and results in lower selectivity [18].

In Fig. 9 we can see that only the secondary alcohol 2heptanol was obtained in the case of the CoAlSi-NHG systems. CoAlSi-NHG-400, which has the highest surface area, led to

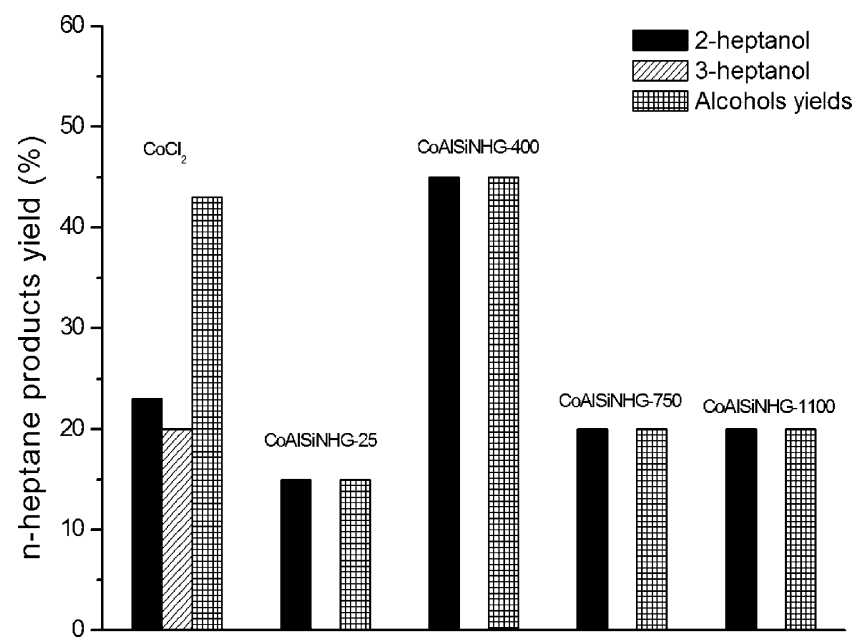

Fig. 9. Catalytic activity of the homogeneous catalyst $\mathrm{CoCl}_{2}$ and CoAlSiNHGs heat-treated at different temperatures in the oxidation of $n$-heptane using $\mathrm{PhIO}$ as oxygen donor. 
the highest yields. When this same reaction was carried out in the presence of $\operatorname{Co}$ (II) salt as catalyst, there was a loss in selectivity, even though only the secondary alcohols 2-heptanol and 3-heptanol were detected.

Some authors have observed that the selective catalytic oxidation of alkanes can be accomplished by means of heterogeneous catalysis [58], where polymeric matrices can control substrate access to the catalyst active site, mimicking biological enzymes. From Fig. 8 it is clear that the aluminum silicate matrix mimics the site isolation principle, thus controlling substrate access to the active site and directing the hydrocarbon for oxidation. This results in higher selectivity than would have been obtained with the neat catalyst.

As reported by Suslick [18] for manganeseporphyrin catalysts, the preferential oxidation of secondary carbons over primary ones can be explained by thermodynamic factors and is consistent with an oxidation mechanism involving formation of the oxo-metal active species. On the other hand, the presence of the aluminum silicate support controls access of the oxo-cobalt species to the substrate, which is oriented in such a way that only the secondary carbon $\mathrm{C} 2$ is oxidized.

\section{Conclusions}

The results reported in this paper clearly show that the nonhydrolitic sol-gel route is a viable way to obtain cobalt aluminum silicate materials and a number of techniques were used to characterize them. The temperature used for the heattreatment of these materials plays an important role in their characteristics. The calcination temperature affects the oxidation state of the cobalt ions and, consequently, the color of the materials. The methodology employed herein enables the formation of the aluminum silicate mullite, which has broad/ wide technological applications, opening up perspectives for using this material in many other areas apart from catalysis.

Catalytic tests performed with the materials obtained via the sol-gel process revealed that this methodology enables the design of efficient and selective heterogeneous catalysts, optimizing the use of cobalt salts as catalysts that are more selective than those currently employed in industry.

The versatile nature of the CoAlSi-NHG systems in the face of the oxidation of different substrates employed in this work, such as the alkene ( $Z$ )-cyclooctene, the cyclic hydrocarbon cyclohexane, and the linear $n$-alkane $n$-heptane, gives strong evidence that oxo-cobalt is the active species responsible for oxygen atom transfer from the oxidant to the studied substrates, as in the case of cytochrome P450 enzymes.

Despite the fact that the oxygen source used in this work, $\mathrm{PhIO}$, is considered to be environmentally hazardous, it was very useful in the study of the mechanisms possibly involved in the generation of the intermediate active species, revealing that cobalt plays an essential role in generating the active intermediate. The use of radical scavengers also ruled out the involvement of active radicalar species, which are usually formed in the presence of transition metals. The presence of the aluminum silicate matrix was useful for modulating the selectivity of catalysts based on cobalt salts.
These results open up wide perspectives for the use of the NHG sol-gel methodology in the design of more efficient and selective catalysts that could be employed in the presence of environmentally friendly oxidants, such as hydrogen peroxide and molecular oxygen. Such studies are underway in our laboratory.

\section{Acknowledgements}

The authors are grateful to FAPESP, CNPq and CAPES (Brazil) for financial support.

\section{References}

[1] M.M. Ramirez-Corredores, Appl. Catal., A 197 (2000) 3.

[2] J.S. Rafelt, J.H. Clark, Catal. Today 57 (2000) 3.

[3] R.A. Sheldon, I.W.C.E. Arends, H.E.B. Lempers, Catal. Today 41 (1998) 387.

[4] K.M. Choi, S. Ikeda, S. Ishino, K. Ikeue, M. Matsumura, B. Ohtani, Appl. Catal., A 278 (2005) 269.

[5] Z.L. Lu, E. Lindner, H.A. Mayer, Chem. Rev. 102 (2002) 3543.

[6] J.A. Cusumano, J. Chem. Educ. 72 (1995) 959.

[7] A.E. Shilov, G.B. Shuĺpin, Chem. Rev. 97 (1997) 2879.

[8] J.T. Groves, J. Porphyrins Phthalocyanines 4 (2000) 350.

[9] E. Torres, I. Bustos-Jaimes, S. Le Borgne, Appl. Catal., B 46 (2003) 1.

[10] A.T. Papacídero, L.A. Rocha, B.L. Caetano, E. Molina, H.C. Sacco, E.J. Nassar, Y. Martinelli, S. Nakagaki, K.J. Ciuffi, Colloids Surf. A 275 (2006) 27.

[11] U. Schuchardt, W. Carvalho, E.V. Spinacé, Synlett 10 (1993) 713.

[12] R. Rinaldi, U. Schuchardt, J. Catal. 227 (2004) 109.

[13] D. Mandelli, M.S.A. van Vliet, R.A. Sheldon, U. Schuchardt, Appl. Catal., A 219 (2001) 209.

[14] L. Zhou, J. Xu, H. Miao, F. Wang, X. Li, Appl. Catal., A 292 (2005) 223.

[15] F. Trifiró, F. Cavani, Catal. Stud. 419 (1994) 350.

[16] J.M. Thomas, R. Raja, G. Sankar, R.G. Bell, Acc. Chem. Res. 34 (2001) 191.

[17] J.T. Groves, in: P.R.O. de Montellano (Ed.), Models and Mechanisms of Cytochrome P-450 Action, third ed., Kluwer Academic/Plenum, New York, 2004, pp. 1-44.

[18] K.S. Suslick, in: K.M. Kadish, K.M. Smith, R. Guilard (Eds.), The Porphyrin Handbook, vol. 4, Academic Press, New York, 2000 pp. 41-63.

[19] R.A. Reziq, D. Avnir, I. Miloslavski, H. Schumann, J. Blum, J. Mol. Catal. A: Chem. 185 (2002) 179.

[20] A.P. Wight, M.E. Davis, Chem. Rev. 102 (2002) 3589.

[21] Z.L. Lu, E. Lindner, H. Mayer, Chem. Rev. 102 (2002) 3543.

[22] A. Godelitsas, D. Charistos, C. Tsipis, P. Misaelides, A. Filippidis, M. Schindler, Microporous Mesoporous Mater. 61 (2003) 69.

[23] M. Hartmann, L. Kevan, Chem. Rev. 99 (1999) 635-663.

[24] R. Bechara, D. Balloy, J. Dauphin, J. Grimblot, Chem. Mater. 11 (1999) 1703.

[25] R.J.P. Corriu, D. Leclercq, P. Lefèvre, P.H. Mutin, A. Vioux, J. Non-Cryst. Solids 146 (1992) 301.

[26] R.J.P. Corriu, D. Leclercq, P. Lefèvre, P.H. Mutin, A. Vioux, J. Sol-Gel Sci. Technol. 8 (1997) 89.

[27] J.N. Hay, H.M. Raval, J. Mater. Chem. 8 (1998) 1233, 22.

[28] J.N. Hay, H.M. Raval, J. Sol-Gel Sci. Technol. 13 (1998) 109, 23.

[29] R.J.P. Corriu, D. Leclercq, P. Lefèvre, P.H. Mutin, A. Vioux, Chem. Mater. 4 (1992) 961.

[30] R.J.P. Corriu, D. Leclercq, Angew. Chem., Int. Ed. Engl. 35 (1996) 1420.

[31] L. Ji, J. Lin, H.C. Zeng, J. Phys. Chem. B 104 (2000) 1783.

[32] R. Bechara, D. Balloy, J.Y. Dauphin, J. Grimblot, Chem. Mater. 11 (1999) 1703.

[33] O.J. de Lima, A.T. Papacídero, L.A. Rocha, H.C. Sacco, E.J. Nassar, K.J. Ciuffi, L.A. Bueno, Y. Messaddeq, S.J.L. Ribeiro, Mater. Charact. 50 (2003) 101. 
[34] S. Acosta, R.J.P. Corriu, D. Leclercq, P. Lefèvre, P.H. Mutin, A. Vioux, J. Non-Cryst. Solids 170 (1994) 234.

[35] J.G. Sharefkin, H. Saltzmann, Org. Synth. 43 (1963) 62.

[36] H.J. Lucas, E.R. Kennedy, M.W. Forno, Org. Synth. 43 (1963) 483.

[37] S. Brunauer, P.H. Emmett, E. Teller, J. Am. Chem. Soc. 60 (1938) 309.

[38] M. Dalibart, J. Deroualt, Coord. Chem. Rev. 74 (1986) 1.

[39] S. Thomson, V. Luva, R. Howe, Phys. Chem. Chem. Phys. 1 (1999) 615.

[40] M. Zayat, D. Levy, Chem. Mater. 12 (2000) 2763.

[41] P. Conception, J.M.L. Nieto, Catal. Commun. 2 (2001) 363.

[42] P.A. Barrett, G. Sankar, C. Richard, A. Catlow, J.M. Thomas, J. Phys. Chem. 100 (1996) 8977.

[43] D.M.A. Melo, J.D. Cunha, J.D.G. Fernandes, M.I. Bernardi, M.A.F. Melo, A.E. Martinelli, Mater. Res. Bull. 38 (2003) 1559.

[44] C. Gerardin, S. Sundaresan, J. Benziger, A. Navrotsky, Chem. Mater. 6 (1994) 160.

[45] M. Panneerselvam, K.J. Rao, Chem. Mater. 15 (2003) 2247.

[46] D.P. Serrano, R. van Grieken, J. Mater. Chem. 11 (2001) 2391.

[47] A. Vioux, Chem. Mater. 9 (1997) 2292.
[48] Z. Luan, C. Cheng, W. Zhou, J. Klinowski, J. Phys. Chem. 99 (1995) 1018.

[49] J.D. Koola, J.K. Kochi, J. Org. Chem. 52 (1987) 4545.

[50] J.T. Groves, J. Inorg. Biochem. (2006).

[51] M.P. Coles, C.G. Lugmair, K.W. Terry, T.D. Tilley, Chem. Mater. 12 (2000) 122.

[52] R.G. Pearson, J. Am. Chem. Soc. 85 (1963) 3533.

[53] I. Fernandez, J.R. Pedro, A.L. Roselló, R. Ruiz, I. Castro, X. Ottenwaelder, Y. Journaux, Eur. J. Org. Chem. 7 (2001) 1235-1247.

[54] D. Mansuy, Coord. Chem. Rev. 125 (1993) 129-142.

[55] J.S. Daniels, K.S. Gates, J. Am. Chem. Soc. 118 (1996) 3380-3385.

[56] T. Punniyamurthy, M.M. Reddy, S.J.S. Kalra, J. Iqbal, Pure Appl. Chem. 68 (1996) 619-622.

[57] U. Schuchardt, D. Cardoso, R. Sercheli, R. Pereira, R.S. Da Cruz, M.C. Guerreiro, D. Mandelli, E.V. Spinacé, E.L. Pires, Appl. Catal., A 211 (2001) 1.

[58] M.A. Martinez-Lorente, P. Battioni, W. Kleemiss, J.F. Bartoli, D. Mansuy, J. Mol. Catal. A: Chem. 113 (1996) 343-353. 